\title{
Coral responses in single- and mixed-species plots to nutrient disturbance
}

\author{
Romeo M. Dizon, Helen T. Yap* \\ The Marine Science Institute, University of the Philippines, Diliman, 1101 Quezon City, The Philippines
}

\begin{abstract}
Space is a limiting resource in coral reef communities causing actively growing coral colonies to come in proximity and interact with each other. Although most contact interactions among corals have been studied extensively, very few non-contact and non-aggressive interactions have been documented so far. We present results from a $3 \mathrm{yr}$ field study of coral communities showing that, under unperturbed conditions, the reef-building coral Porites cylindrica exhibits significantly higher growth when transplanted together with 2 other species ( $P$. rus and Pavona frondifera) than when grown in monoculture. However, the introduction of a chronic disturbance (nutrient enrichment) adversely affected its growth rates and survival, thus overturning the earlier trend. Furthermore, the 3 species used in the experiment exhibited different responses to the perturbation (negative, no effect, positive). Our results show that the presence of other species can enhance performance at the colony level, while differential species responses potentially provide buffering effects at the community level that may contribute to the maintenance of community structure and function during periods of disturbance.
\end{abstract}

KEY WORDS: Species number · Biological interactions $\cdot$ Competition $\cdot$ Neighbor effect $\cdot$ Coral growth . Nutrient loading

Resale or republication not permitted without written consent of the publisher

\section{INTRODUCTION}

Reef-building corals constitute a diverse functional group that alters the reef environment by their physical structure, thereby providing habitats for other organisms and potentially supporting high levels of local diversity (Lawton \& Jones 1995). The aggregate growth of individual coral colonies, over geologic time, gives rise to the major structural framework of the reef via the process of accretion. But the process of reef-building is also under the influence of various physico-chemical and biological variables that affect the growth of individual coral colonies and, consequently, the rates and patterns of carbonate accumulation at the community level.

The available space in the reef substratum is very limited; thus, interaction between actively growing organisms, such as corals, is inevitable. Both inter- and intraspecific competition among corals have been the most intensively studied types of such interactions (reviewed in Lang \& Chornesky 1990). These may take the form of contact competition, such as the develop- ment of mesenterial filaments, sweeper tentacles (e.g. Bak et al. 1982, Tanner 1997) and overgrowth (Lang \& Chornesky 1990 and references therein), or noncontact competition, such as overtopping (e.g. Baird \& Hughes 2000), peripheral encircling (Lang \& Chornesky 1990) and allelopathy (e.g. Koh \& Sweatman 2000). However, not all coral interactions are necessarily aggressive and inhibitory, as has been documented by a limited number of studies. Rinkevich \& Loya (1985), for example, suggested that chemical signaling takes place between branches of Stylophora pistillata that are growing in proximity to each other. Closely growing intraclonal branch pairs either change their direction of growth ('reverse growth') or cease growing, while those that are already in contact fuse together. Chornesky (1991) reported that inter- and intraclonal contact between colonies of the foliaceous coral Agaricia tenuifolia growing in high-energy environments rendered the interacting colonies more resistant to breakage and detachment. Raymundo (2001) observed higher growth rates in Porites attenuata 
transplants that were growing beside live conspecifics than those that were transplanted beside dead ones.

Positive and non-aggressive interactions among sessile organisms are not unusual in nature (Stachowicz 2001, Bruno et al. 2003). They have been documented in terrestrial and subaquatic plant communities (e.g. Bertness \& Hacker 1994, Callaway et al. 2002), in aquatic macrophytes (e.g. Barrat-Segretain \& Arnaud 2004) and in marine systems (Stachowicz 2001). If competitive interactions are the main structuring force in stable, constant environments, the effects of which are erased by disturbances (Bak et al. 1982), then positive interactions, on the other hand, may arise as 'the simple by-product of neighbors buffering one another from potentially limiting physical stresses' (Bertness \& Hacker 1994).

The present study was designed to test the effect of live coral neighbors of the same and different species on the growth responses of transplanted corals. We monitored the growth and survival of individual coral colonies in artificially assembled communities ('grid experiment') and subsequently introduced a chronic perturbation in the form of nutrient enrichment to evaluate how a disturbance would affect organismal processes and persistence within a community. To verify results from the unperturbed phase of the experiment, we also monitored corals transplanted to natural communities ('transplant experiment') for $1 \mathrm{yr}$.

To distinguish between the effects of interspecific and intraspecific interactions among the transplants, 2 treatment levels were employed in both experiments: a single-species and a mixed-species (=3) treatment. The primary experimental species, the branching coral Porites cylindrica, occurs in coral patches that exhibit a wide range of diversity levels. It is known to form distinct zones on the reef that are either characterized by extensive monospecific thickets (Veron 2000) or by low-diversity patches (where it still constitutes one of the dominant taxa [authors' personal observations]). Although it also thrives in high-diversity communities, each $P$. cylindrica colony is more often in direct interaction with only a few other coral species (i.e. $~ 3$ ), as was observed in the transplant experiment (see 'Materials and methods'). The experiments were designed to test if the presence of other species in a system can have effects on colony performance that would translate to the community level and produce possible buffering effects against perturbations, as predicted by the insurance hypothesis of biodiversity (Yachi \& Loreau 1999). This hypothesis maintains that, in fluctuating environments, higher species numbers produce a higher temporal mean for ecosystem processes (= performance enhancement) and, at the same time, provide a smaller temporal variance about this mean (i.e. buffering effect) due to the asynchrony of species responses to environmental variations.

\section{MATERIALS AND METHODS}

Coral transplants. Three coral species were used in the experiments (Porites cylindrica, P. rus and Pavona frondifera). They were selected based on the following criteria: (1) natural occurrence at the study site (to make sure that all species were native to the experimental area), (2) differences in growth forms ( $P$. cylindrica is arborescent, $P$. rus, encrusting/submassive and $P$. frondifera, foliose), (3) ability to establish monospecific patches (true for $P$. cylindrica which was used for the 'single-species treatment') and (4) likelihood of the 3 species to occur together in natural communities (to make certain that the species used in the experiments have a history of interaction). These criteria were set to ensure that the assemblages in the experiments were similar to natural communities.

Coral transplants were prepared from nubbins, knobs, or branches cut from parent colonies in the field. Each cutting was attached at its base to a $5 \times 5 \mathrm{~cm}$ acrylic tile using a hot-melt adhesive, taking care to expose only a minimal area of live tissue to the molten glue. In all cases, the coral transplants recovered quickly from the transplant-preparation process and grew over the adhesive in a matter of weeks. Species treatments were of 2 kinds: a 'single-species' treatment in which only nubbins of 1 species, Porites cylindrica, were established in a plot and a '3-species' treatment in which nubbins from all 3 species were included in a plot (see next subsection). These 2 treatment levels were primarily determined by logistical constraints posed by the availability of species from which adequate samples could be taken and by the necessity of making repeated measurements on all the samples over the 3 yr experimental period.

Grid experiment. All experiments were conducted inside the Carót Marine Sanctuary in the BolinaoAnda reef system, NW Philippines $\left(16^{\circ} 22.82^{\prime} \mathrm{N}\right.$, $\left.119^{\circ} 59.69^{\prime} \mathrm{E}\right)$. Artificial plots were set up in a reef flat in September 1999 and consisted of 12 wire-mesh grids of $1 \mathrm{~m}^{2}$ that were randomly deployed in pairs at a mean depth of $4.5 \mathrm{~m}$. Each grid in every set of 4 was 1 replicate of a treatment (single- or 3-species, enriched or unenriched). In each grid, 30 transplants were attached more or less equidistantly from each other $(\sim 10 \mathrm{~cm}$ apart) using plastic-coated tie wire. A total of 30 Porites cylindrica nubbins were on each single-species grid, while 10 nubbins each of $P$. cylindrica, $P$. rus and Pavona frondifera were interspersed on each 3species grid. The corals were periodically brought to the laboratory for buoyant-weight measurements (Davies 1989) and for branch-tip counts (P. cylindrica only) until October 2002. In September 2000 (1 yr after transplantation), nutrient enrichment was introduced to half of the grids using porous terracotta flowerpots 
(mouth diameter: $12 \mathrm{~cm}$ ) as nutrient diffusing substrates (modified from Wootton et al. 1996). The pots were filled with $170 \mathrm{~g}$ of commercial fertilizer $(\mathrm{N}-\mathrm{P}-\mathrm{K}$ ratio: 14:14:14). These were sealed at the drain hole and at the open end and fastened to the grids (4 pots grid $^{-1}$ ) using tie wire. The pots were scrubbed of algae weekly and were replaced with new pots monthly to ensure a continuous delivery of nutrients throughout the duration of the experiment. Water samples were collected from representative grids and from the water column (i.e. $1 \mathrm{~m}$ below the surface) before flowerpot deployment and 2, 3, 7, 14, 21 and $28 \mathrm{~d}$ after. Water samples were analyzed for $\mathrm{NO}_{2}+\mathrm{NO}_{3}$ and $\mathrm{PO}_{4}$ concentrations using a Skalar autoanalyzer following Strickland \& Parsons (1972).

Other physico-chemical parameters that were measured include light, sedimentation rates, salinity, water turbulence and temperature. Ambient light was measured monthly using a spherical quantum light sensor (Li-Cor SPQA 0760) that was placed at the level of the grids while sedimentation rates were quantified using sediment traps (length $=25 \mathrm{~cm}$, inner diameter $=5 \mathrm{~cm}$ ). Water samples were collected from depths of 1 and $4.5 \mathrm{~m}$ for salinity measurements using a WTW conductivity meter. Temperature was continuously recorded by a StowAway TidbiT submersible temperature logger. Water motion was measured using calcium sulfate clod cards in two $24 \mathrm{~h}$ deployments to cover a complete tidal cycle (Doty 1971).

Transplant experiment. Three $10 \mathrm{~m}$ permanent transects were laid across natural coral patches at an average depth of $4 \mathrm{~m}$ in September 2002. Two transects were laid across monospecific Porites cylindrica stands, and a third, across a mixed-species coral patch. Along 1 monospecific transect (designated as the control transect), 30 single-tipped and intact branches of $P$. cylindrica were marked $30 \mathrm{~mm}$ from the growing end with cable ties and tagged with labeled tie wire. In the other monospecific transect, 30 single-tipped, marked and tagged $P$. cylindrica branches were transplanted by attaching them to the substratum (using Portland cement) within a distance of $5 \mathrm{~cm}$ from intact and naturally occurring $P$. cylindrica colonies. The same number of $P$. cylindrica branches were transplanted into the mixed-species transect in which each transplant was adjacent to at least 2 other coral species (within $5 \mathrm{~cm}$ ). The transplants were measured every quarter for linear extension (mean distance from the cable tie to the primary branch tips) and for branching indices (branch tip counts per quarter normalized by initial branch counts) until October 2003 (total observation period of $1 \mathrm{yr}$ ).

Statistical analyses. Growth rates from the buoyantweight data, as well as the branching rates, were subjected to analysis of variance with repeated measures
(ANOVAR) (Potvin et al. 1990), which, unlike standard ANOVA, can analyze within-subject variability (multiple measures of a parameter from the same subject). Using data on buoyant weight, branching index (for Porites cylindrica) and total carbonate accumulation rate (aggregate skeletal growth rate per grid) from the grid experiment, comparisons were made between 1 -species and 3-species treatments before the addition of nutrients (species numbers: 2 levels, repeated measurements: 5 levels) and between the enriched and unenriched treatments upon nutrient addition (species numbers: 2, nutrient treatment: 2, repeated measurements: 3). Linear extension rates and branching indices were likewise compared among the control nubbins and the treatment nubbins (monospecific and mixed-species) in the transplant experiment using ANOVAR. In most analyses, if Mauchly's sphericity criterion was not met, the Huynh-Feldt- or Greenhouse-Geisser-corrected significance values were used. However, in cases of strong violations of the sphericity criterion, results from the accompanying MANOVA were reported, using Pillai's trace as the test statistic (Potvin et al. 1990). Helmert contrasts were also carried out to determine which time intervals yielded significant differences among the various treatment groups (Potvin et al. 1990). Survival data were analyzed using the Kaplan-Meier product limit estimate, and differences between survival curves were assessed using the log-rank test (Lee 1992). Physico-chemical parameters were analyzed along with the growth data (buoyant weight and branching indices) using multiple correlation (Zar 1984). All ANOVAR tests were carried out with SAS Learning Edition (SAS Institute 2002), while multiple-correlation and survival data analyses were done using SPSS, Ver. 11 (SPSS 2001).

\section{RESULTS}

Initial counts of Porites cylindrica branch tips were not significantly different among the grids (2-way ANOVA, $F_{5,107}=0.300, \mathrm{p}=0.912$ ) or between monospecific and mixed-species treatments $\left(F_{1,107}=0.095\right.$, $\mathrm{p}=0.759$ ). Although initial buoyant-weight measurements showed that there were weight differences between species, there were no significant differences among the grids $\left(F_{5,354}=0.397, \mathrm{p}=0.851\right)$.

Under unperturbed conditions, growth rates of Porites cylindrica were significantly higher in the presence of other species. Buoyant-weight measurements in the grid experiment showed that $P$. cylindrica had significantly higher growth rates in the 3-species plots than in the pure $P$. cylindrica plots (ANOVAR, $F_{1,10}=$ 5.700, $p=0.038$; Table 1, Fig. 1A). This resulted in 


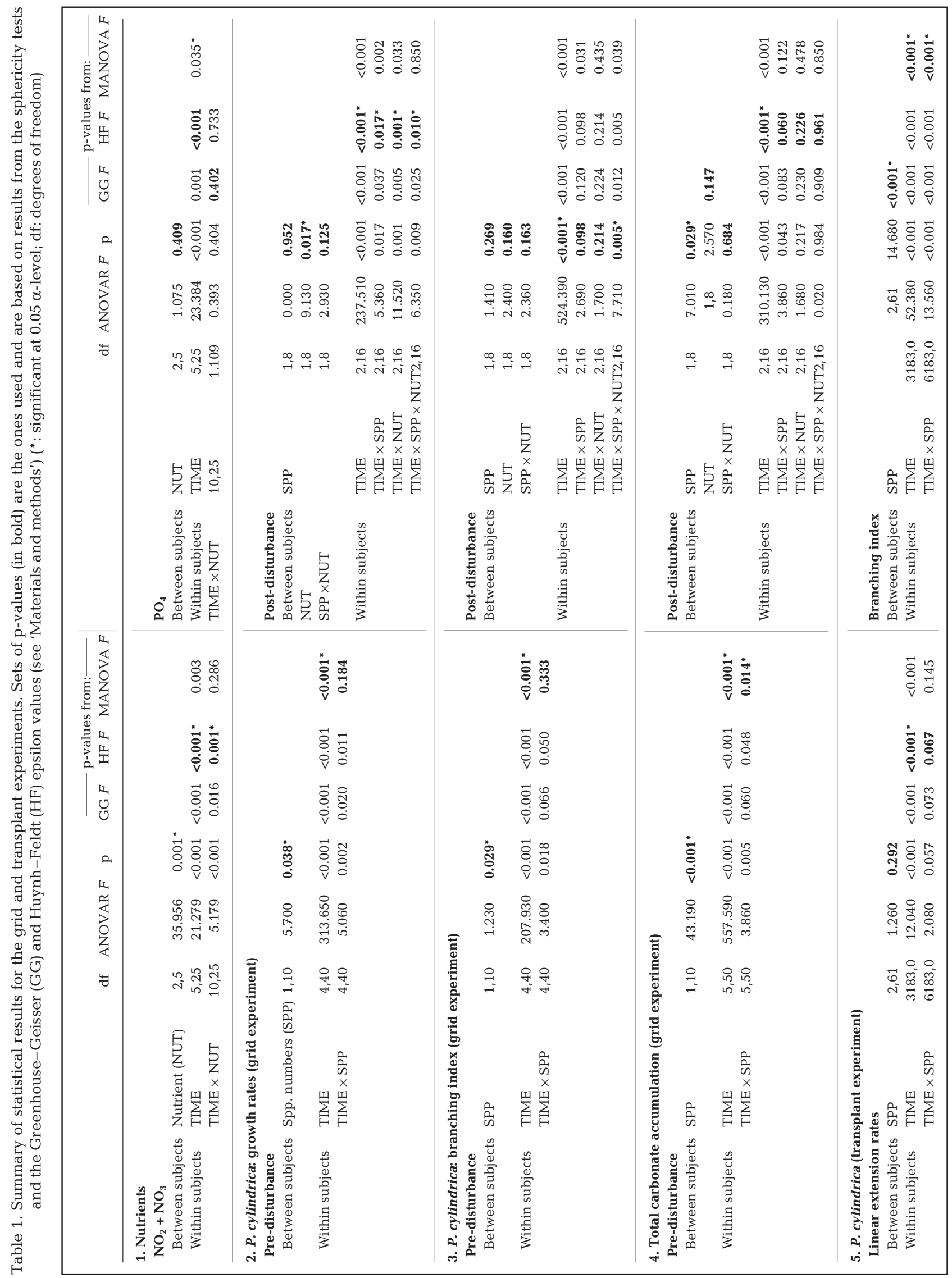




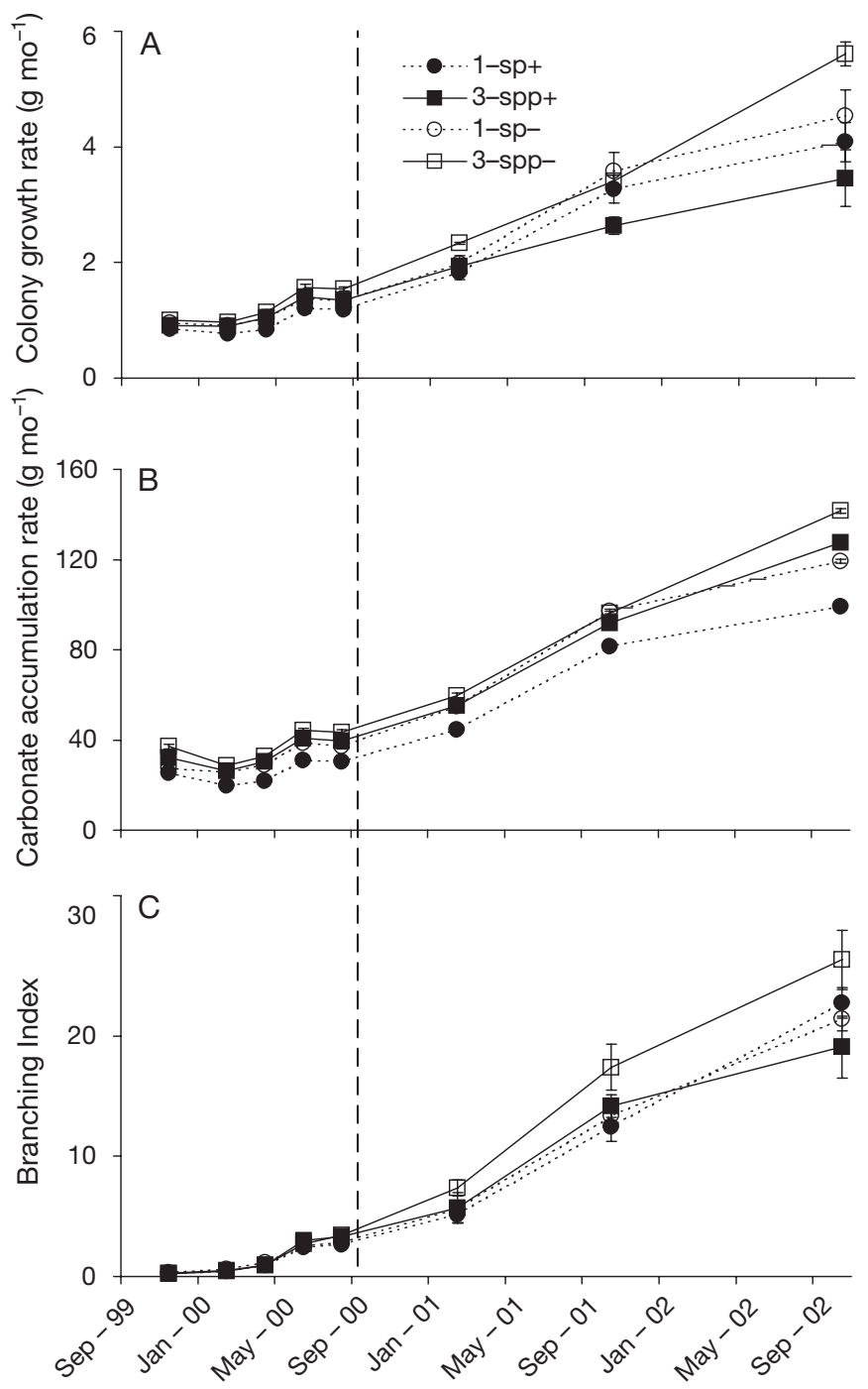

Fig. 1. Porites cylindrica. Mean growth responses $( \pm \mathrm{SE})$ of coral colonies to proximate neighbors and to nutrient enrichment in the grid experiment. Dashed vertical line indicates commencement of nutrient treatment (September 2000). (A) Pre- and postdisturbance growth rates of $P$. cylindrica in treated $(+)$ and untreated $(-), 1$-species and 3-species plots. (B) Total carbonate accumulation of all corals in a plot (as measured by combined skeletal growth). (C) Branching indices of $P$. cylindrica colonies (grid experiment)

higher total skeletal deposition (sum of all corals in a grid) (ANOVAR, $F_{1,10}=43.190, \mathrm{p}<0.001$; Table 1, Fig. 1B). Branching indices likewise showed significant effects of species number (ANOVAR, $F_{1,10}=1.230$, $\mathrm{p}=0.029$; Table 1, Fig. 1C). In the transplantation experiment, which involved no perturbation, the corals transplanted to mixed-species patches also had the highest branching rates relative to the controls and the monospecific patches (ANOVAR, $F_{2,61}=14.680, \mathrm{p}<$ 0.001; Table 1, Fig. 2A) although linear extension rates did not show any significant between-treatment differ-
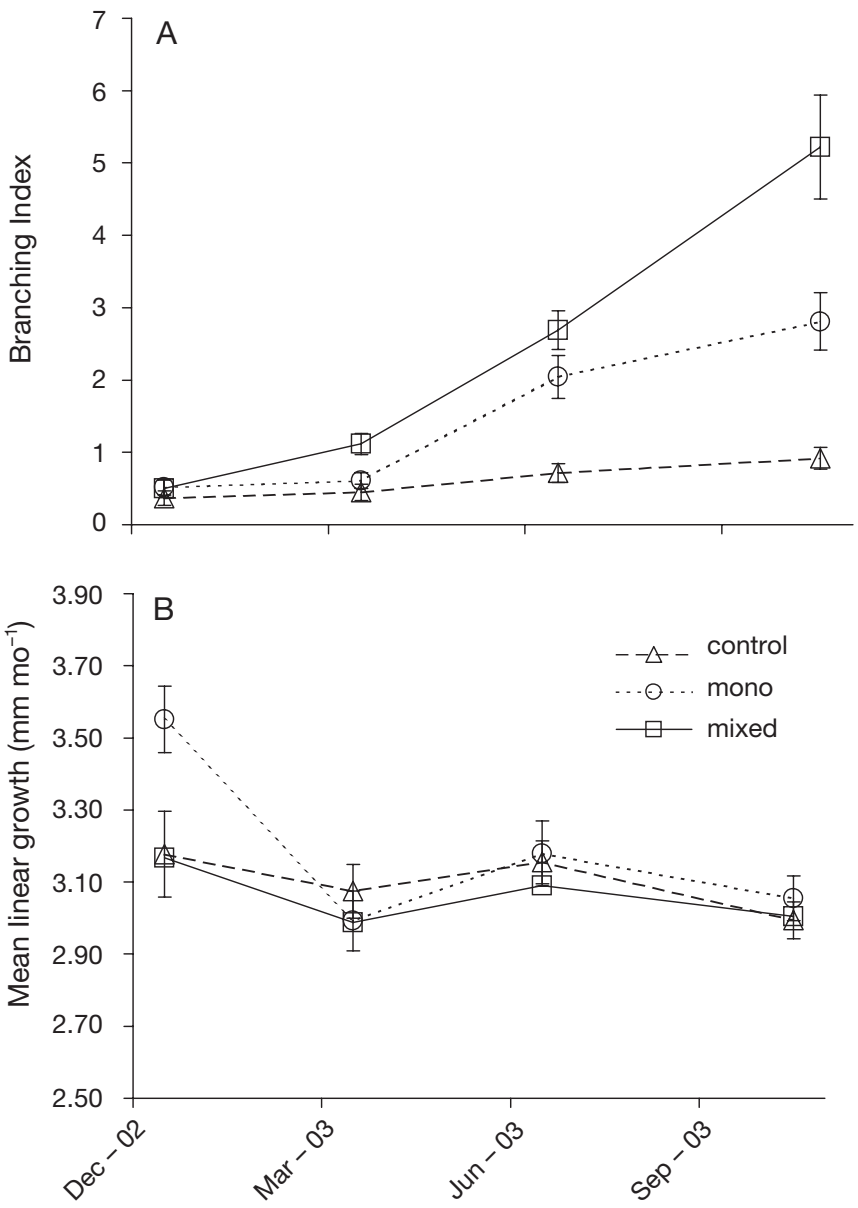

Fig. 2. Porites cylindrica. (A) Mean branching indices and (B) linear growth rates of transplants in the control, monospecific and mixed-species plots (transplantation experiment, $\mathrm{n}=30$ ). Bars are standard errors

ences (Table 1, Fig. 2B). Environmental parameters, such as light, sedimentation rates, salinity, water turbulence and temperature, varied more as a function of time than of space (i.e. between treatments and among replicate grids). Multiple linear correlation analyses confirmed that there was no linear dependence of growth or of branching rates on most of these factors except for temperature, which negatively correlated with growth rates (2-tailed Pearson correlation, $\mathrm{p}<0.05)$.

During the nutrient-enrichment phase, $\mathrm{NO}_{2}+\mathrm{NO}_{3}$ levels in the treated grids (range: 0.25 to $2.04 \mu \mathrm{M}$ ) were significantly higher than in the control grids (range: 0.32 to $1.00 \mu \mathrm{M}$ ) and in the water column (range: 0.15 to $1.00 \mu \mathrm{M})\left(\right.$ ANOVAR, $F_{2,5}=35.956, p=0.001$; Table 1). Increased levels were sustained in the immediate vicinity of the enriched grids over a period of 28 d. $\mathrm{PO}_{4}$ levels, however, did not differ significantly between treatments (ANOVAR, $F_{2,5}=1.075, \mathrm{p}=0.409$; Table 1). 


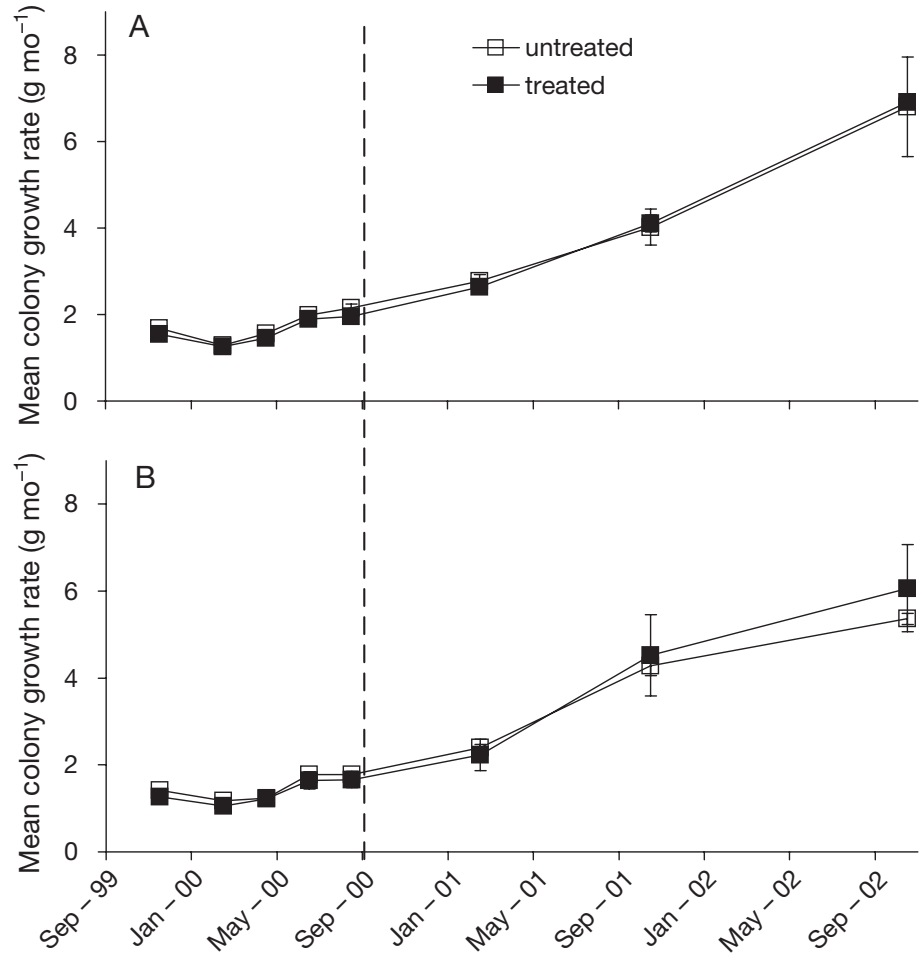

Fig. 3. Pavona frondifera and Porites rus. Mean growth rates $( \pm$ SE) of coral colonies in treated $(\square)$ and untreated $(\square)$ mixed-species grids: (A) $P$. frondifera (no nutrient effect on growth) and (B) P. rus (showing a post-disturbance increase in growth rates in the nutrient-treated plots; Helmert contrasts for the last time interval [October 2001 to October 2002], $\mathrm{p}<0.05)$

Upon addition of the nutrients, differences between the single-species and 3-species treatments in terms of buoyant-weight increase in Porites cylindrica in the grid experiment became less apparent over time, while differences between the nutrient-treated (enriched) and the control grids became more distinct (ANOVAR, $F_{1,8}=9.130, \mathrm{p}=0.017$; Table 1, Fig. 1A). Over the course of the enrichment phase, we observed a marked decrease in the mean growth rates of $P$. cylindrica in the nutrient-enriched grids (both single- and 3-species treatments) (Fig. 1A).

Interestingly, the responses of the 2 other species to nutrient addition in terms of growth were different from that of Porites cylindrica. Pavona frondifera showed no observable responses to the disturbance (Fig. 3A), while Porites rus exhibited growth enhancement towards the end of the experiment (Fig. 3B). Although an ANOVAR test did not detect a significant effect of nutrient addition on the overall growth trend of $P$. rus (ANOVAR, $F_{1,4}=0.01, \mathrm{p}=0.928$ ), Helmert contrasts revealed a significant difference between the growth rates of enriched and unenriched colonies in the last time interval (October 2001 to October 2002, $\mathrm{p}=0.025)$.
Prior to the application of the nutrient treatment, survival rates of Porites cylindrica in both mixed- and single-species grids remained relatively high and did not significantly differ from each other (Fig. 4). However, upon nutrient addition, survival rates in the mixed-species treatments were found to decrease significantly compared to those in the monoculture (logrank test, $\mathrm{p}=0.02$ ), succumbing more readily to algal overgrowth and gastropod grazing.

\section{DISCUSSION}

Among the various abiotic variables that were measured, only temperature was found to be significantly and negatively correlated with coral growth. Subsequent regression analyses showed that temperature explained at least $75 \%$ of the variability in growth and branching rates over time. This relationship has been established previously for corals (e.g. Yap \& Gomez 1984) and does not affect the general trends observed in this study.

Coral interactions, mainly in the form of competition, are generally known to have negative effects at the colony and species levels, affecting growth, reproduction and fitness (Tanner 1997). There is evidence that these interactions are mediated by chemical cues (Rinkevich \& Loya 1985, Koh \& Sweatman 2000). On the other hand, growth enhancement of corals due to neighbor effects is believed to involve similar signals

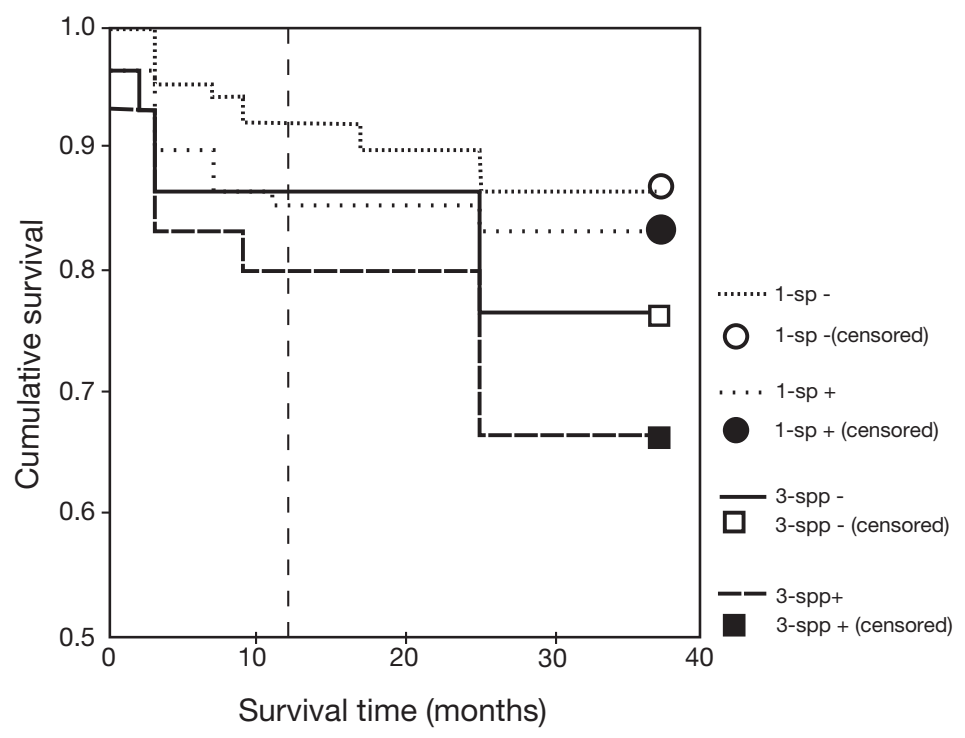

Fig. 4. Porites cylindrica. Survival function of colonies transplanted to single-species grids (1-sp; circles) and to 3-species grids (3-spp; squares). Enriched and unenriched treatments are indicated by filled and open symbols, respectively. Dashed vertical line indicates time at which nutrient treatment commenced 
(Raymundo 2001). The higher growth rates and branching indices observed in this study of Porites cylindrica growing with other species is not necessarily explained by merely a release from intraspecific competition. In the transplantation experiments of Raymundo (2001), using a species closely related to (and often confused with) P. cylindrica, P. attenuata grew faster (although branched less) when transplanted beside live conspecifics than when transplanted beside dead coral fragments.

Corals may make use of increased growth as a competitive strategy against other species (Baird \& Hughes 2000), a response that is probably similar to the 'shade avoidance syndrome' in plants (Pierik et al. 2003). Thus, the high growth and branching rates of Porites cylindrica are most likely competitive, yet non-aggressive, responses to the presence of live coral neighbors belonging to different species. P. cylindrica is a poor contact competitor compared to $P$. rus and Pavona frondifera. In adjacent colonies that were in direct physical contact, we observed that $P$. cylindrica exhibited necrotic tissue at the zones of contact in all cases. Since $P$. rus and $P$. frondifera were growing faster (although spreading more slowly) than P. cylindrica, immediate occupation of the available lateral space by the latter may serve to keep the more aggressive corals at bay and protect its inner branches to allow subsequent and unhindered vertical growth. This response was demonstrated in both the grid and transplant experiments in which $P$. cylindrica corals in the mixedspecies plots sprouted significantly more branches than those growing in the monospecific plots.

In the transplant experiment, suppression of branching was most evident in the control plots, where the coral branches remained attached to their mother colonies (Fig. 2A). This suggests that a signaling system (transmitted via the water medium or between coral polyps within an intact colony) is in place that directs the mode and rate of colony growth (Rinkevich \& Loya 1985). In mixed-species communities, enhanced growth and branching resulting from competitive interaction not only potentially produce localized enhancement of carbonate deposition (eventually contributing to the structural growth of the reef), but also benefit coral-associated organisms by providing more spaces for shelter, thus promoting local diversity. This provides a good example of the positive effects of species richness at the organismal and community levels.

Many corals respond negatively to nitrogen loading, with a reduction in growth rates (Ferrier-Pagès et al. 2000, Koop et al. 2001). In our experiments, only Porites cylindrica exhibited sensitivity to the levels of enrichment used in the experiment and experienced depressed growth rates upon exposure to these levels. Pavona frondifera, on the other hand, remained un- affected, while Porites rus showed a post-disturbance increase in mean growth rates in the nutrient-treated plots. As a result, total carbonate accumulation rates in the 3-species plots remained higher than those in the single-species treatments despite the decreased growth rates and increased mortality of $P$. cylindrica in these mixed-species plots. This indicates a possible buffering effect at the community level.

Our results indicate that the negative effects of the enrichment eventually prevailed over the pre-disturbance benefits of the presence of more species. As the Porites cylindrica colonies channeled greater proportions of their energy into competitive growth, overall colony fitness decreased and rendered the corals more vulnerable to other external stresses (in this case, nutrient enrichment).

As was observed in this study, not all species within a functional group respond similarly to the same stimulus. Different species exhibit disparate thresholds to perturbation independent of the community context (Koop et al. 2001, Pfisterer \& Schmid 2002). This variation in species responses to perturbation is believed to provide the mechanism for the buffering effect of species diversity on ecosystem function (Yachi \& Loreau 1999). In the present study, we used monospecific and 3-species communities, both of which are still considered to be at the lower end of the species-diversity continuum in a typical coral reef. However, despite the small difference in diversity, significant differences were already detected. Future experiments considering more species $(\geq 10)$ should be able to further verify the insurance effects of diversity. Higher species numbers provide for a wider range of tolerance to stresses at the community level, thus insuring, to some extent, the persistence of functional groups in the face of perturbations. 'Degeneracy' (Solé et al. 2003), sometimes referred to as 'redundancy', in ecosystems provides them with a capacity to track or withstand environmental and ecological fluctuations by allowing species within the same functional groups to compensate for species that are either physiologically impaired or lost to the system in a perturbation event. However, with the increasing effect of human-generated, human-enhanced and human-altered disturbances constantly impinging on ecosystems (Vitousek et al. 1997, Nyström et al. 2000, Knowlton 2001, Hughes et al. 2003), variability in species sensitivities might not be enough to insure the persistence of these systems as the various species thresholds to perturbations are increasingly breached.

Acknowledgements. We thank the SAMUSECA and the municipal government of Anda for facilitating our work within the Carót Marine Sanctuary, M. Ponce for assistance in the field, I. Velasquez for help in the nutrient analyses, N. Kautsky for the temperature loggers and J. Ogden and E. D. 
Gomez for invaluable advice during the study. This research was supported by the International Society for Reef StudiesCenter for Marine Conservation (ISRS-CMC 1998 Student Fellowship Award) and the International Foundation for Science (IFS Grant A/3099-1). This is contribution 341 of The Marine Science Institute.

\section{LITERATURE CITED}

Baird AH, Hughes TP (2000) Competitive dominance by tabular corals: an experimental analysis of recruitment and survival of understorey assemblages. J Exp Mar Biol Ecol 251:117-132

Bak RPM, Termaat RM, Dekker R (1982) Complexity of coral interactions: influence of time, location of interaction and epifauna. Mar Biol 69:215-222

Barrat-Segretain MH, Arnaud E (2004) Experiments on growth interactions between 2 invasive macrophyte species. J Veget Sci 15:109-114

Bertness MD, Hacker SD (1994) Physical stress and positive associations among marsh plants. Am Nat 144:363-372

Bruno JF, Stachowicz JJ, Bertness MD (2003) Inclusion of facilitation into ecological theory. Trends Ecol Evol 18:119-125

Callaway RM, Brooker RW, Choler P, Kikvidze Z and 9 others (2002) Positive interactions among alpine plants increase with stress. Nature 417:845-848

Chornesky EA (1991) The ties that bind: inter-clonal cooperation may help a fragile coral dominate shallow highenergy reefs. Mar Biol 109:41-51

Davies PS (1989) Short-term growth measurements of corals using an accurate buoyant weighing technique. Mar Biol 101:389-395

Doty MS (1971) Measurement of water movement in reference to benthic algal growth. Bot Mar 14:32-35

Ferrier-Pagès C, Gattuso JP, Dallot S, Jaubert J (2000) Effect of nutrient enrichment on growth and photosynthesis of the zooxanthellate coral Stylophora pistillata. Coral Reefs 19:103-113

Hughes TP, Baird AH, Bellwood DR, Card M and 13 others (2003) Climate change, human impacts and the resilience of coral reefs. Science 301:929-933

Knowlton N (2001) The future of coral reefs. Proc Natl Acad Sci 98:5419-5425

Koh EGL, Sweatman H (2000) Chemical warfare among scleractinians: bioactive natural products from Tubastraea faulkneri Wells kill larvae of potential competitors. J Exp Mar Biol Ecol 251:141-160

Koop K, Booth D, Broadbent A, Brodie J and 16 others (2001) ENCORE: the effect of nutrient enrichment on coral reefs: synthesis of results and conclusions. Mar Pollut Bull 42: 91-120

Lang JC, Chornesky EA (1990) Competition between scleractinian reef corals - a review of mechanisms and effects. In: Dubinsky Z (ed) Ecosystems of the world, Vol 25. Coral reefs. Elsevier, Amsterdam

Editorial responsibility: Charles Birkeland (Contributing Editor), Honolulu, Hawaii, USA
Lawton JH, Jones CG (1995) Linking species and ecosystems: organisms as ecosystem engineers. In: Jones CG, Lawton $\mathrm{JH}$ (eds) Linking species and ecosystems. Chapman \& Hall, New York

Lee ET (1992) Statistical methods for survival data analysis, 2nd edn. John Wiley \& Sons, New York

Nyström M, Folke C, Moberg F (2000) Coral reef disturbance and resilience in a human-dominated environment. Trends Ecol Evol 15:413-417

Pfisterer AB, Schmid B (2002) Diversity-dependent production can decrease the stability of ecosystem functioning. Nature 416:84-86

Pierik R, Visser EJW, De Kroon H, Voesenek LACJ (2003) Ethylene is required in tobacco to successfully compete with proximate neighbours. Plant Cell Environ 26:1229-1234

Potvin C, Lechowicz MJ, Tardif S (1990) The statistical analysis of ecophysiological response curves obtained from experiments involving repeated measures. Ecology 71: $1389-1400$

Raymundo LJ (2001) Mediation of growth by conspecific neighbors and the effect of site in transplanted fragments of the coral Porites attenuata Nemenzo in the central Philippines. Coral Reefs 20:263-272

Rinkevich B, Loya Y (1985) Coral isomone: a proposed chemical signal controlling intraclonal growth patterns in a branching coral. Bull Mar Sci 36:319-324

SAS Institute (2002) SAS enterprise guide, Version 1.3. SAS Institute, Cary, NC

Solé RV, Cancho RF, Montoya JM, Valverde S (2003) Selection, tinkering and emergence in complex networks. Complexity 8:20-33

SPSS (2001) SPSS for Windows, Release 11.0. SPSS, Chicago

Stachowicz J (2001) Mutualism, facilitation and the structure of ecological communities. BioScience 51:235-246

Strickland JDH, Parsons TR (1972) A practical handbook of sea-water analysis, 2nd edn. Bull Fish Res Board Can 167: $1-311$

Tanner JE (1997) Interspecific competition reduces fitness in scleractinian corals. J Exp Mar Biol Ecol 214:19-34

Veron JEN (2000) Corals of the world, Vol 3. Australian Institute of Marine Science, Townsville

Vitousek PM, Mooney HA, Lubchenco J, Melilo JM (1997) Human domination of earth's ecosystems. Science 277: 494-499

Wootton JT, Power ME, Paine RT, Pfister CA (1996) Effects of productivity, consumers, competitors, and El Niño events on food chain patterns in a rocky intertidal community. Proc Natl Acad Sci USA 93:13855-13858

Yachi S, Loreau M (1999) Biodiversity and ecosystem productivity in a fluctuating environment: the insurance hypothesis. Proc Natl Acad Sci USA 96:1463-1468

Yap HT, Gomez ED (1984) Growth of Acropora pulchra. II. Responses of natural and transplanted colonies to temperature and day length. Mar Biol 81:209-215

Zar JH (1984) Biostatistical analysis, 2nd edn. Prentice-Hall, Englewood Cliffs, NJ

Submitted: June 1, 2004; Accepted: February 8, 2005

Proofs received from author(s): June 26, 2005 